\title{
Using ICD-10 diagnostic codes to identify 'missing' paediatric patients during nationwide COVID-19 lockdown in Oxfordshire, UK
}

\author{
James E. G. Charlesworth ${ }^{1,2,3}$ (D) Rhian Bold $^{1,2} \cdot$ Rani Pal $^{1}$ \\ Received: 25 February 2021 / Revised: 11 May 2021 / Accepted: 13 May 2021 / Published online: 26 May 2021 \\ (C) The Author(s), under exclusive licence to Springer-Verlag GmbH Germany, part of Springer Nature 2021
}

\begin{abstract}
The study aims to identify 'missing' diagnoses amongst paediatric admissions during the UK's first national lockdown, compared with the previous 5 years. A retrospective observational cohort study of all children $(0-15$ years $)$ attending for urgent care across Oxfordshire, during the first UK lockdown in 2020, compared to matched dates in 2015-2019, across two paediatric hospitals providing secondary care, including one with tertiary services. Our outcome measures were changes in numbers of patients attending and inpatient diagnoses (using ICD-10 classification) during the first 2020 lockdown, compared with the previous 5 years, were used. We found that total Emergency Department (ED) attendances $(n=4030)$ and hospital admissions $(n$ $=1416$ ) during the first UK lockdown were reduced by $56.8 \%$ and $59.4 \%$, respectively, compared to 2015-2019 (5-year means $n$ $=7446.8$ and $n=2491.6$, respectively). Proportions of patients admitted from ED and length of stay were similar across 20152020. ICD-10 diagnoses in lockdown of $2020(n=2843)$ versus matched 2015-2019 dates $(n=19,946)$ demonstrated significantly greater neoplasm diagnoses $(p=0.0123)$. Of diagnoses 'missing' in lockdown, $80 \%$ were categorised as infectious diseases or their sequelae and $20 \%$ were non-specific pains/aches/malaise and accidental injury/poisonings.

Conclusions: Pandemic public health measures significantly altered paediatric presentations. Oxfordshire hospitals had a 58\% reduction in ED attendances/inpatient admissions, with 'missing' diagnoses predominantly infection-related illnesses. These are likely driven by a combination of the following: (1) public health infection control measures successfully reducing disease transmission, (2) parents/carers keeping mild/self-limiting disease at home, and (3) pandemic-related healthcare anxieties. Prospective studies are needed to ensure referral pathways identify vulnerable children, those with social concerns, and avoid delayed presentation.
\end{abstract}

Communicated by Peter de Winter

James E. G. Charlesworth

James.charlesworth@doctors.org.uk

Rhian Bold

rhian.bold@ouh.nhs.uk

Rani Pal

rani.pal@ouh.nhs.uk

1 Oxford University Hospitals NHS Foundation Trust (John Radcliffe and Horton Hospitals), Oxfordshire, UK

2 Oxford University Clinical Academic Graduate School (OUCAGS), John Radcliffe Hospital, University of Oxford, Oxford, UK

3 Milton Keynes University Hospital NHS Foundation Trust, Milton Keynes, UK 
Keywords Lockdown $\cdot$ COVID-19 $\cdot$ Paediatric admissions $\cdot$ ICD-10 $\cdot$ Missing patients

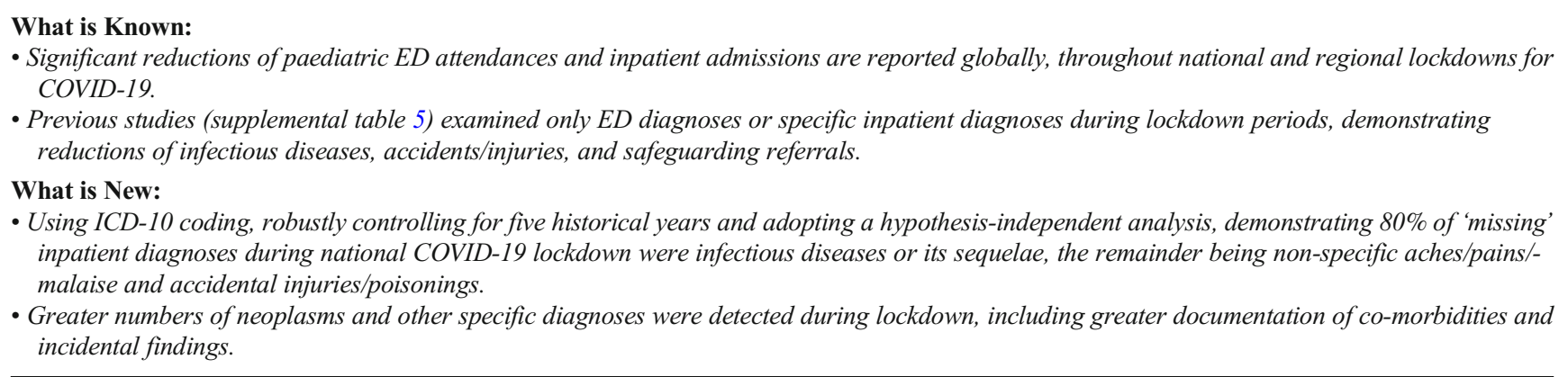

\section{Introduction}

The impact of the COVID-19 pandemic on global health issues requires constant review of public health measures. In 2020, the United Kingdom implemented the first set of national restrictions for asymptomatic individuals after the recognition of COVID-19 transmissibility, mortality risk, and excess burden on the healthcare system. On 16 March, these included advice against non-essential travel, reducing contact between households, ban on visiting social venues, and 'work from home' initiative [1]. On 20 March, the hospitality sector was closed to dining-in and schools closed except to key workers' children. Lastly, on 23 March, a 'stay at home' order was implemented and is recognised as the start of the first national lockdown, continuing until 12 May. From 13 May, significant restrictions remained in place with limited interaction permitted between households, despite a cautious return to work.

Internationally, varying levels of lockdown restriction has led to reductions in paediatric emergency department (ED) attendances of around 50\% (24.9-88\%) [2-14]. Many authors expressed concern about children who may be 'lost' to secondary services during lockdowns, particularly those with concerning or significant disease [4, 5, 10, 14-16]. Although children are deemed to be relatively unaffected by primary SARS-CoV-2 infection [17], pandemic measures/messaging are altering patterns of paediatric disease presentation. Recent studies during the 2020 winter months show significant declines in admissions for bronchiolitis, respiratory infections, and gastroenteritis compared to previous years $[18,19]$.

Few studies suggest an internationally comparable way to continuously report on patients not attending for hospital care. Our study sought to clarify the effects of the first UK lockdown on paediatric ED attendances and hospital admissions in Oxfordshire, UK, using ICD-10 (International Statistical Classification of Diseases and related health problems 10) codes from electronic patient records. We aim to identify diagnoses that were 'missing' during lockdown in 2020, compared to the previous 5 years (2015-2019).

\section{Methods}

Data was extracted from electronic healthcare records for all patients aged $0-15$ years attending ED and any urgent admission under specialist services across Oxfordshire University Hospitals NHS Foundation Trust's two sites (Horton General Hospital, Banbury, and John Radcliffe Hospital, Oxford). Data collection occurred 3 weeks prior to, inclusive of, and 2 weeks after the first national UK lockdown period (02/03/ 2020-26/05/2020), and matched periods in 2015-2019 (02/ 03/2015-26/05/2015, 07/03/2016-24/05/2016, 06/03/2017$23 / 05 / 2017,05 / 03 / 2018-29 / 05 / 2018$, and 04/03/2019-28/ $05 / 2019$ ). Dates used for lockdown data were $23 / 03 / 2020$ $12 / 05 / 2020$. The matched 49 days for 2015-2019 begin on 23/03/2015, 28/03/2016, 27/03/2017, 26/03/2018, and 25/03/ 2019. Matched dates included the same number of weekdays/ weekends, beginning on the nearest Monday to the 2020 date.

Diagnoses using ICD-10 classification are assigned by clinical coders. ICD-10 codes were matched with chapter headings and specific diagnoses using https://icd.codes/ icd $10 \mathrm{~cm}$. To our knowledge, there was no substantial change to clinical coding during the 6-year study period. Due to software limitations, the first ten diagnoses for each patient were extracted. Patients are assigned a primary diagnosis, whereas concomitant diagnoses (e.g. viral illness, wheeze) and historical diagnoses add relevant context to the complexity of patients. Therefore, all diagnostic codes were included for most of our analyses. Two patients without a discharge date (from 2019) had length of stay censored at extraction; patients without discharge diagnoses are documented (0-9 patients/year; Supplemental Table 1). 
A diagnosis of 'COVID-19, virus identified' (ICD-10 code U071) was made only five times during the 2020 lockdown period (never for dates outside of lockdown). COVID-19 was grouped under ICD-10 chapter 1 (infectious and parasitic diseases), and the sub-heading 'other viral diseases'.

Additional data included date of birth, postcode, length of stay (LOS), and source of admission. Postcode was used for assessing Index of Multiple Deprivation Rank, calculated using the UK government online tool (http://imd-bypostcode.opendatacommunities.org/imd/2019).

Information used for clinical audit in May 2020 followed Trust procedures to access anonymised patient data. NHS Health Research Authority for ethics committee review and approval were not required.

Data were handled in Microsoft Excel (Office 365). Graphical presentation of data was prepared in GraphPad Prism (Version 9.0.0 for Windows, San Diego, California, USA). Statistical analyses were performed in GraphPad Prism and SPSS (Version 27.0. for Windows, IBM, NY, USA). Multiple testing corrections were performed where necessary. Non-parametric testing was used throughout; significance was taken as $p<0.05$.

\section{Results}

\section{ED attendances and inpatient admissions reduced during lockdown, without increased severity of admissions}

We observed significant reductions in paediatric ED attendances and inpatient admissions across both Oxfordshire hospitals, compared with 2015-2019 (Fig. 1A-B). Pre-lockdown admissions reduced by $22.6 \%(p=0.05)$ were lowest during the first week of lockdown $(62.1 \%$ fewer, $p<0.0001)$ and maintained throughout (supplemental figure 1). These reductions were consistent across Oxfordshire (supplemental figure $2 \mathrm{~A}-\mathrm{F}$ ) and were reduced in all age groups (age $<1$ year$48.4 \%, 1-5$ years $-67.2 .4 \%, 6-10$ years- $53.3 \%$, and $11-$ 15 years - $48.9 \%$; supplemental figure $2 \mathrm{G}-\mathrm{J}$ ). The socioeconomic background of ED attendees was similar across all years 2015-2020, as assessed by postcode-derived index of multiple deprivation rank (supplemental figure 3).

We examined for surrogates of disease severity. Reductions in admissions from all sources were matched by reductions in admissions from ED alone (Fig. 1C); the proportion of ED attendees requiring admission was similar for each year (approximately 20\%, Fig. 1D), and consistent between hospitals (supplemental figure 2K-L). Mean subsequent LOS, based on day of admission, was similar for patients admitted during lockdown ( $1.95 \pm 0.338$ days) compared with previous years (1.94 \pm 0.120 days) (Fig. 1E). A surrogate of severity of illness was the number of diagnoses per patient: a mean of
$71.6 \%$ received $>2$ ICD-10 diagnoses (mean 4.81 diagnoses/ patient) in lockdown versus $44.5 \%$ (2.97 diagnoses/patient) in 2015-2019 (Fig. 1F-G). Greater proportions in 2020 were given $\geq 10$ diagnoses ( $13.1 \%$ versus $1.3-4.1 \%$ in 2015 2919) (Fig. 1G; supplemental figure 4).

\section{Diagnoses amongst inpatients were decreased in 8 of 20 ICD-10 chapters during lockdown}

ICD-10 chapter headings provide diagnostic groups for children admitted in 2020 (Fig. 2; supplemental table 2). Significant reductions were observed for five of six of the most commonly diagnosed groups and eight of 20 chapter headings, compared with 2015-2019. Notable reductions in diagnoses were observed amongst respiratory diseases $(62.4 \%, p<0.0001)$, infectious diseases $(58.9 \%, p<$ $0.0001)$ and injury/poisoning $(52.7 \%, p<0.0001)$. Only 'neoplasms' and 'factors influencing health status and contact with health services' increased in 2020 compared with previous years, by $75.9 \%(p=0.0123)$ and $64 \%(p=0.0004)$, respectively. When primary diagnosis is considered alone (supplemental figure 5), admissions within 11 of 20 chapters were significantly reduced in 2020 . Neoplasms remained significantly increased throughout the lockdown period, whereas 'factors influencing health status' significantly decreased. Changes amongst these chapter headings were consistent week-to-week throughout the lockdown period (supplemental figure 6).

We explored relative changes in patient diagnostic groups admitted during lockdown (by chapter heading; Fig. 3). All diagnoses, and primary diagnoses, demonstrated reductions in the proportions of infectious and respiratory diseases. Similar proportions of non-specific diagnostic groups such as 'factors influencing health status and contact with health services' and 'abnormal clinical or laboratory findings' were observed amongst primary diagnoses in 2020 compared to previous years (Fig. 3, right panels).

\section{Diagnoses 'missing' throughout the 2020 lockdown were predominantly infective illness or sequelae of infectious illness}

To identify specific diagnoses that significantly differed in the seven weeks of lockdown, compared to the same period over the previous 5 years, we assessed differences in weekly admissions for each diagnosis (supplemental table 3 ). All diagnoses in 2015-2019 with a mean $\geq 1$ or any diagnosis made in 2020 were included. There were 726.8 (20.4\%) fewer diagnoses during lockdown versus 2015-2019 $(n=2853$ in 2020 versus mean $n=3569.8$ across 2015-2019). This included significantly more patients with neoplasms admitted in 2020 (Fig. 2), with notable increases for both benign and malignant neoplasms. Sub-group analyses showed a skew toward greater 
A

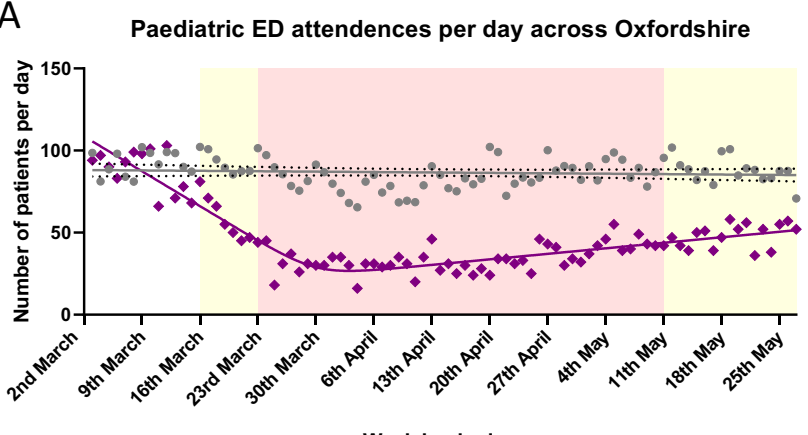

C

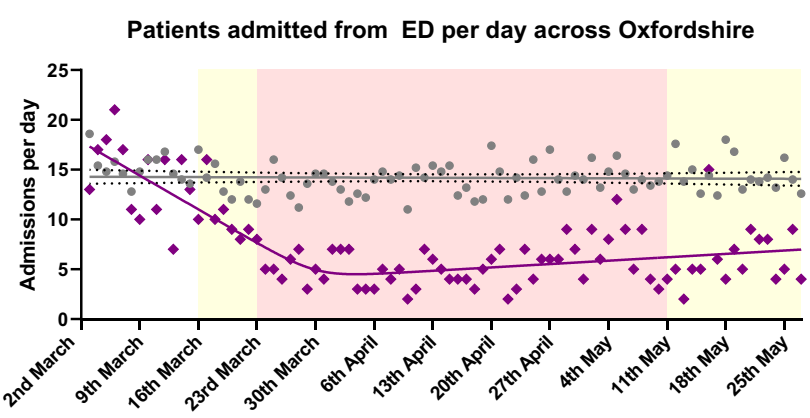

$E$
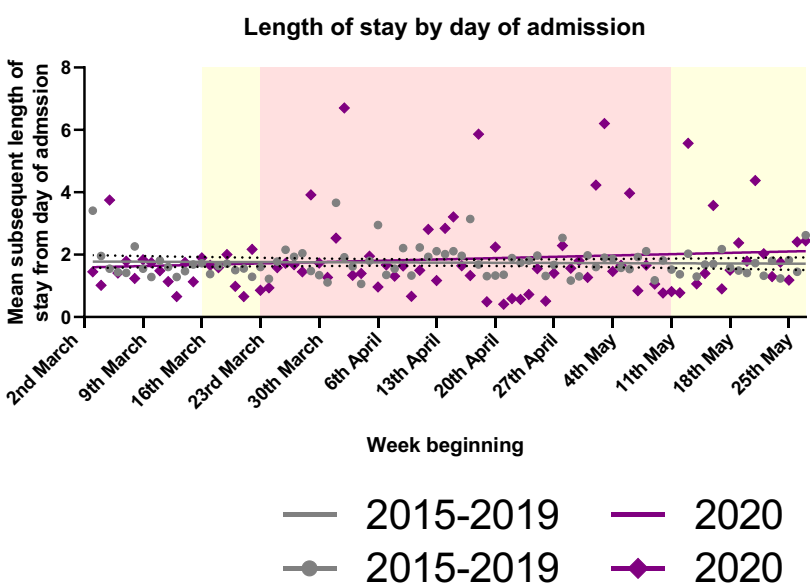

G

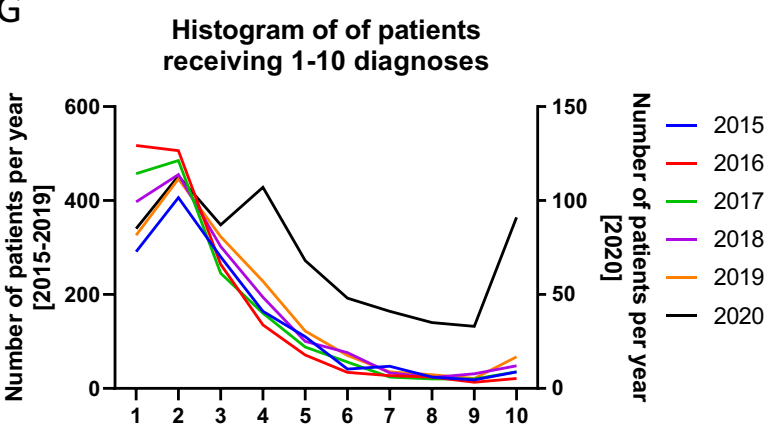

No. of Diagnoses given on discharge

proportions of central nervous system (CNS) tumours, and secondary tumours diagnosed in 2020 (supplemental figure 7). Small but significant increases were observed in diagnoses
B

All paediatric admissions across Oxfordshire

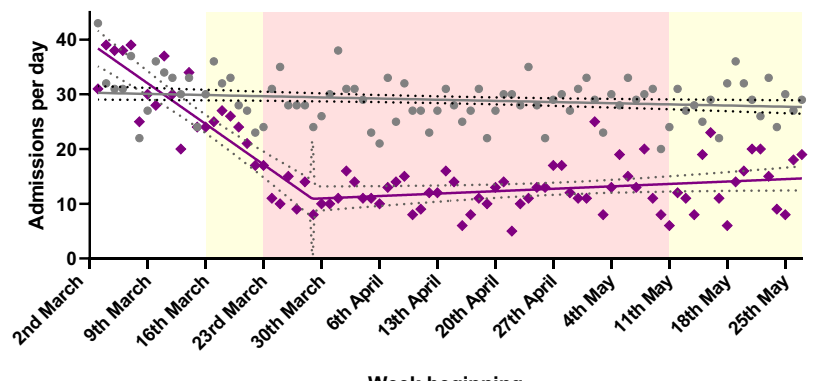

D

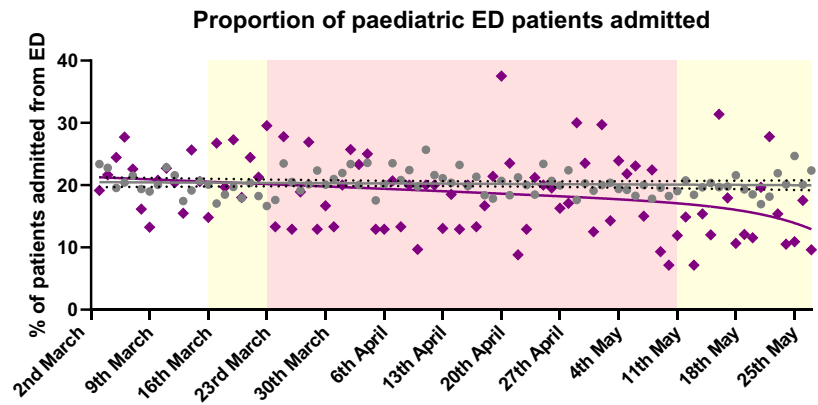

$\mathrm{F}$

Week beginning

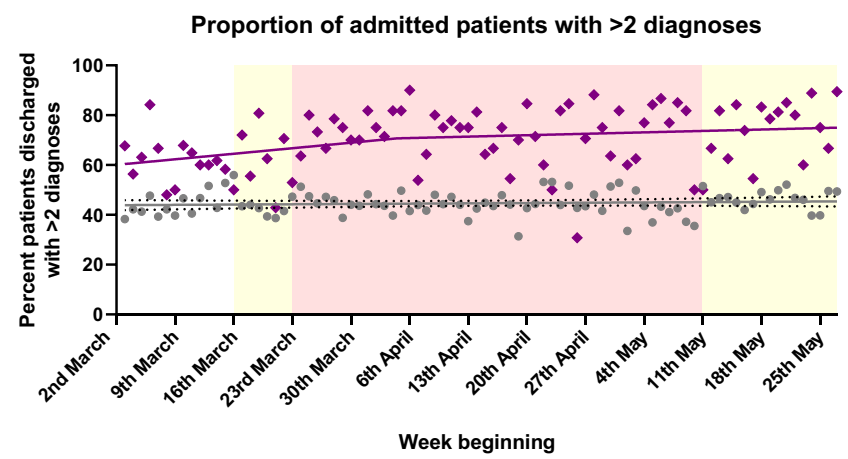

\section{National lockdown period} COVID-19 restrictions of gram-negative sepsis, 'unspecified' appendicitis, and 'other specified' diabetes mellitus in 2020 (supplemental table 3). Sub-group classification was used to identify whether these 
4 Fig. 1 Paediatric ED attendances and admissions during the first national lockdown period in 2020, compared to 2015-2019. The numbers of paediatric ED attendances (A), inpatient admissions (B), and paediatric inpatient admissions referred from ED $(\mathbf{C})$ are shown by day for 2020 (purple) and compared to matched period (mean) 2015-2019 (grey). The proportion admitted from ED (with total ED attendances for the day as a denominator) is shown across the same period (D). For each day of admission, the resulting length of stay is calculated for each patient, and averaged across all patients admitted on the same day $(\mathbf{E})$. Proportions of patients with more than 2 diagnoses on discharge from paediatric wards are shown, based on day of admission $(\mathbf{F})$, with the histogram of the numbers of diagnoses received by year $(\mathbf{G})$. National restrictions on asymptomatic individuals are shown (yellow) with the first national lockdown period (red). Lines of 2015-2019 represent simple linear regression with dotted line demonstrating 95\% confidence. Lines for 2020 are nonlinear segmental regression lines, using least squares fit and continuous hinge function

may result from minor changes in diagnostic assignment for similar diseases (supplemental table 4). This showed no significant increase in any infectious disease subgroup, diseases of the appendix, or diabetes mellitus in 2020 compared to previous years. Amongst mental health diagnoses, significant reductions were observed for anorexia and the intentional selfharm subgroup, without any increased mental health diagnosis in 2020 .

To identify the 'missing' diagnoses during lockdown, significant changes compared with 2015-2019 were categorised (Table 1). Net changes in numbers of diagnoses in 2020, compared with median numbers observed in 2015-2019, were used to demonstrate the degree of change. Diagnoses grouped as 'likely related to pandemic screening', 'likely incidental finding or co-morbidity', and 'other diagnoses' represented $24 \%$ of lockdown diagnoses and increased compared with 2015-2019 (Fig. 4A, right panel). 'Infective illnesses', 'likely sequelae of infective illness', 'non-specific pains, aches and malaise', and 'accidental injury/poisoning' had a net decrease in 2020. Net differences amongst 'missing' diagnoses totalled $n=761$, more than accounting for the 726.8 fewer diagnoses in 2020 compared to the mean of 2015-2019 (Fig. 4A). Infective illnesses and 'likely sequelae of infective illness' accounted for $79.5 \%$ of diagnoses 'missing' from lockdown (Fig. 4B). Amongst infective illnesses, unspecified viral infections accounted for a third of missing diagnoses (Fig. 4C), whilst wheezing, nausea, and vomiting and unspecified asthma together constitute $72 \%$ of decreased diagnoses amongst sequelae of infective illnesses (Fig. 4D).

\section{Discussion}

Public health measures have varied widely internationally, even across the devolved UK nations. As a result, our data may not directly translate to every lockdown scenario. Our data included all acute paediatric admissions but precluded ED diagnoses, which are not classified by ICD-10 criteria. Therefore, extremely rare events or short ED attendances/ observation periods will be under-reported in our data. Our study furthers others published to date (supplemental table 5), in performing a systematic examination of all paediatric inpatients and diagnoses using standardised ICD-10 criteria.

We reviewed 2843 diagnoses associated with 1416 admissions during the first lockdown period in 2020, compared with 12,458 admissions and 19,946 diagnoses across matched dates 2015-2019. We demonstrate decreased paediatric admissions and ED attendances throughout lockdown, with increased numbers of diagnoses per patient. Contrary to others $[5,12]$, the proportions of children admitted from ED were similar in all study years, suggesting comparable clinical severity of ED presentations across all 6 years. However, amongst those admitted a greater proportion received $\geq 10$ diagnoses, suggesting an enrichment of children with complex/severe disease. Diagnoses which significantly increased during lockdown fit three main groups (1) increased documentation of co-morbidities/incidental findings, (2) pandemic screening, and (3) greater detection of 'other' diagnoses. Other diagnoses included benign and malignant neoplasms, similarly observed in German ED patients during their first national lockdown [5]. Urgent admissions increased for patients with malignancies, possibly due to reductions in face-toface primary care capacity, and/or adaptations to tertiary oncology services during the pandemic, with elective admissions restricted.

Our findings have similarities to Germany's first national lockdown, where paediatric diagnoses in Hanover were significantly reduced compared with 2019 for overall hospital admissions, communicable/non-communicable diseases, including intoxication [5]. In contrast, Dopfer et al. found greater proportions of ED patients were admitted, but with similar lengths of stay to 2019.

Significant reductions in infective diseases and personal injuries during international lockdown-like measures are recently reported [7-13]. Our data suggests $80 \%$ of 'missing' diagnoses during lockdown were infective disease or sequelae of infective illness. These most likely resulted from public health pandemic advice, with population adherence to infection control measures, compounded by restricting geographic movement and school closures throughout the first lockdown. Equivalent stringent measures in other countries also resulted in significant reductions in COVID-19 transmission as well as other circulating infectious diseases amongst children, including respiratory and gastrointestinal diseases $[18,19]$. Similar to our findings, reductions in infectious diseases, their sequelae, and personal injuries were reported in paediatric presentations across the UK, Germany, Belgium, France, Italy, USA, South Africa, and Singapore $[5,7,9,12,13,18,19]$. We observed significant reductions in non-specific asthma and wheezing, despite historically high pollen counts during 
Abnormal clinical or laboratory findings
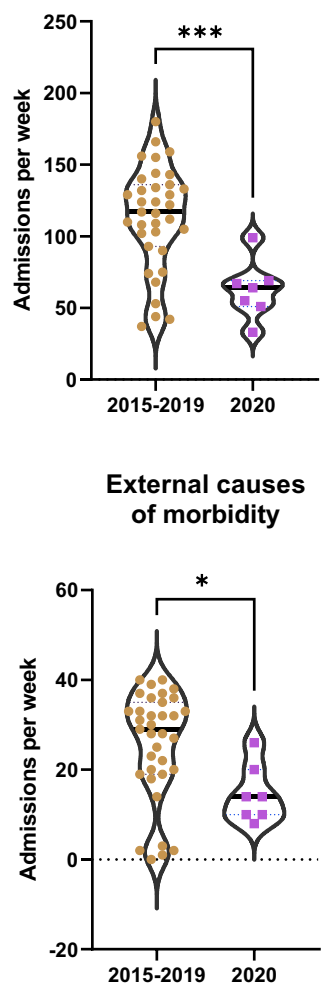

Diseases of the nervous system

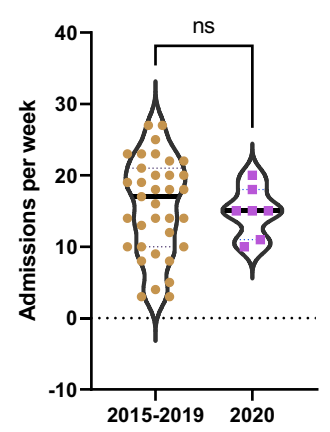

Diseases of the genitourinary system

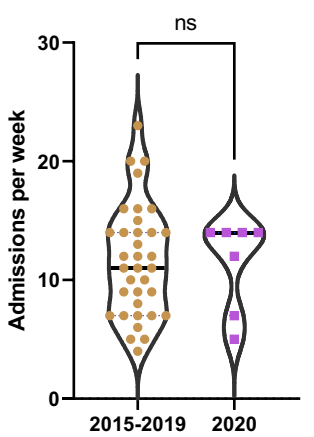

Factors influencing health status

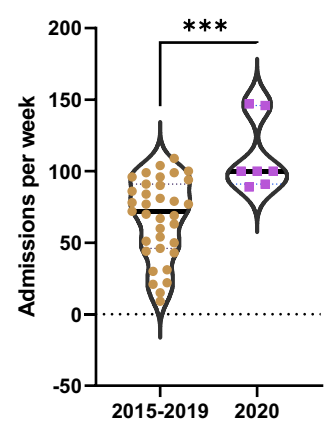

Certain conditions originating in the perinatal period

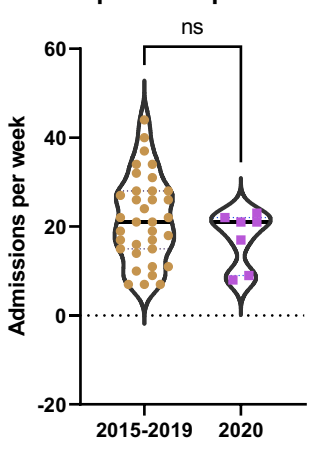

Diseases of the musculoskeletal system and connective tissue

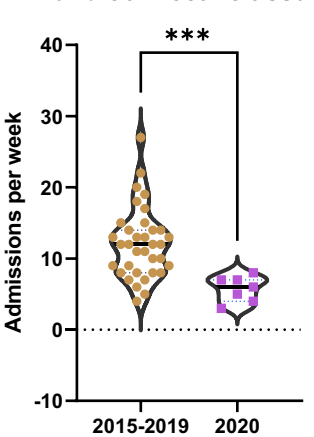

Blood, bone marrow and immunological diseases

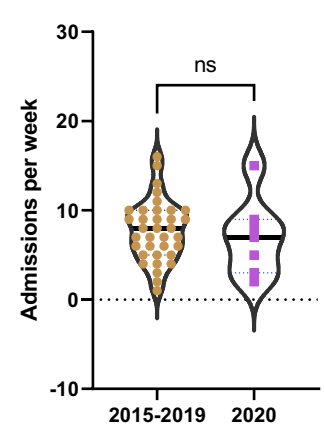

Certain infectious and parasitic diseases

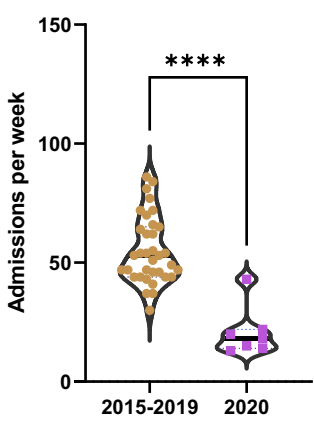

Diseases of the digestive system
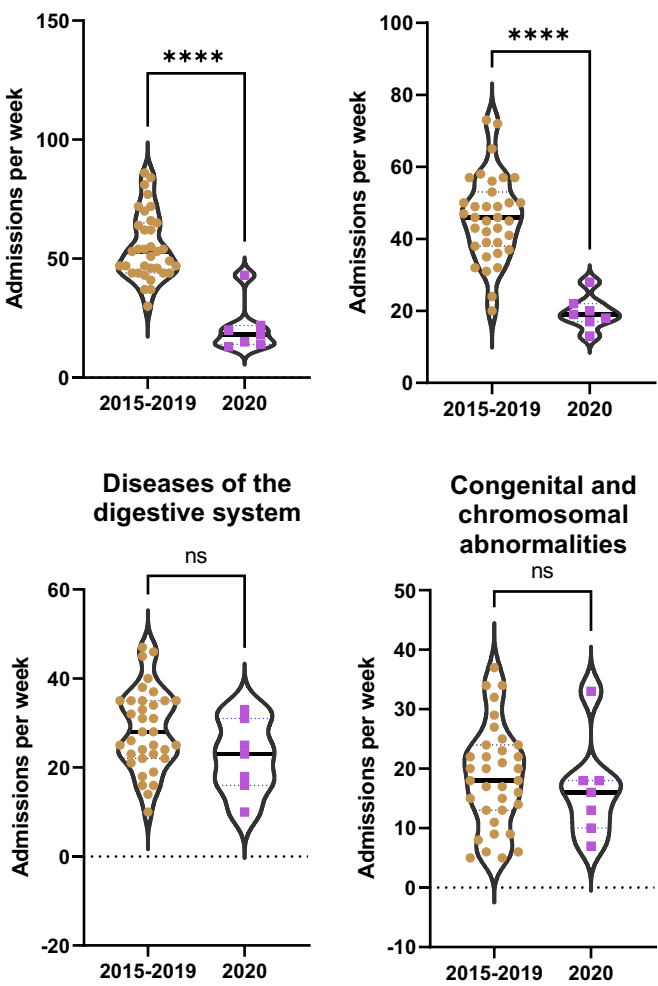

Congenital and chromosomal abnormalities
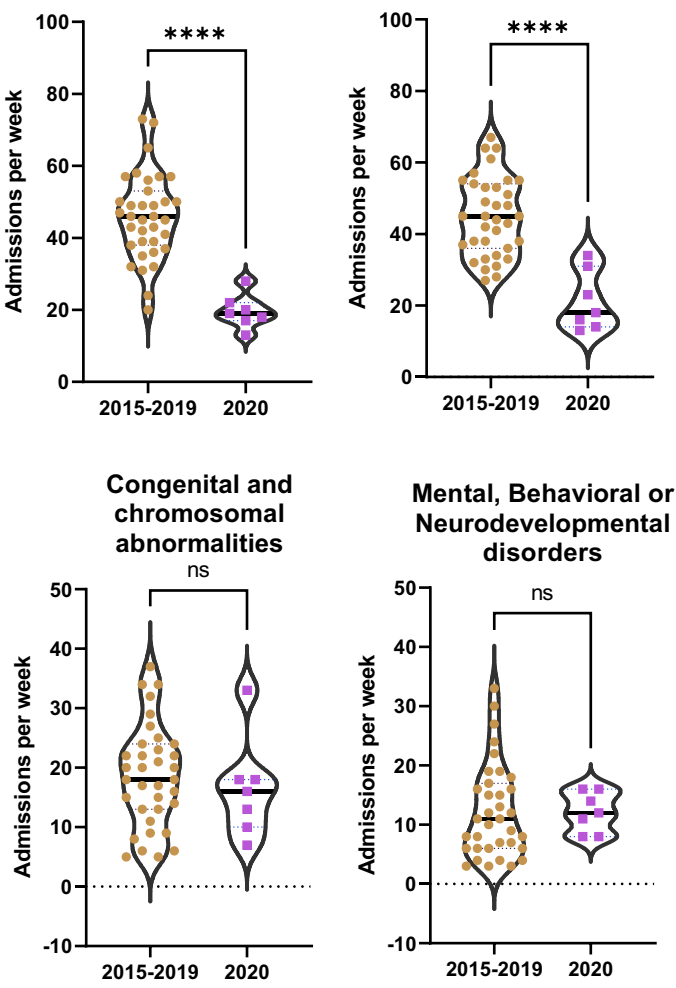

Diseases of the skin and subcutaneous tissue

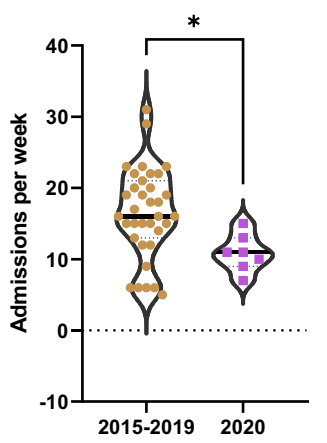

Endocrine, nutritional and metabolic diseases
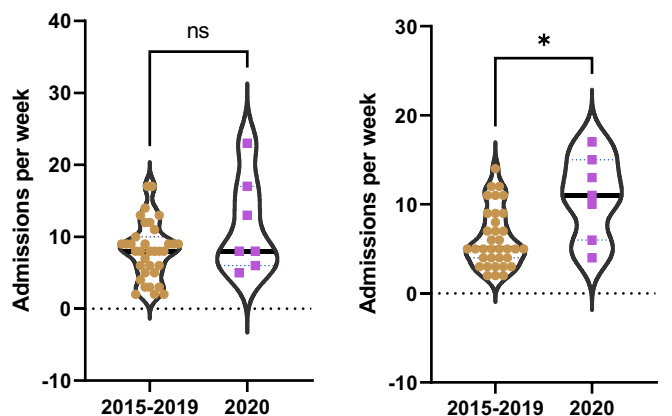

Diseases of the eye and adnexa

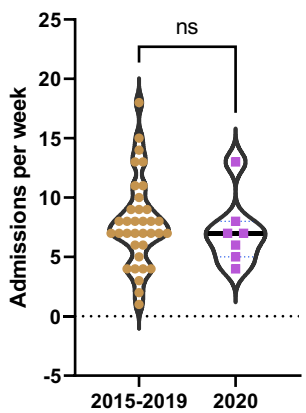

Diseases of the ear and mastoid process

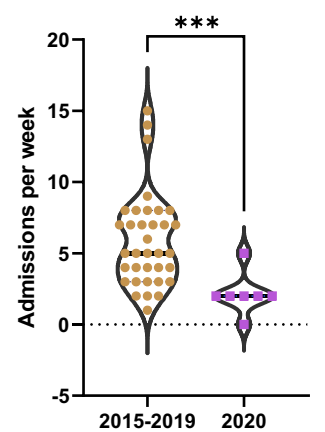

Mental, Behavioral or Neurodevelopmental disorders

Injury, poisoning

and consequences of external causes

Neoplasms

Diseases of the circulatory system

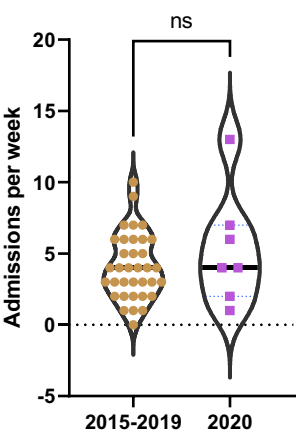


Fig. 2 Changes in numbers of diagnoses made in 2020 compared to 2015-2019 by ICD-10 chapter. Diagnoses by ICD-10 chapter headings. Discharge diagnoses (maximum 10) are shown per week for the first national lockdown period ( $n=7$ weeks, 2020), compared to matched periods during the previous 5 years ( $n=35$ weeks, 2015-2019). Statistical results from Mann-Whitney $U$ test. ns $=$ not significant, $* P<$ $0.05, * * P<0.01, * * * P<0.001, * * * * P<0.0001$

lockdown (Met Office UK, personal communication), reflected by increases in allergic rhinitis $(p=0.0828)$ and allergic asthma $(p=0.0613)$ amongst our data. Both asthma and wheezing are predominantly triggered by infection in children $[20,21]$, so were categorised as sequelae of infectious diseases. However, as these respiratory symptoms are also affected by air quality and pollution [22, 23], which significantly improved during lockdown [24, 25] alongside reduced environmental contacts due to a 'stay at home' policy, multiple factors may have contributed to the reduced asthma and wheeze admissions we observed.

With reduced exposure to infections, parent/carer confidence may increase in treating mildly unwell children with non-specific temperature/pain/aches/malaise for longer periods. Consistent with this hypothesis is an Italian study demonstrating reductions of $84-92 \%$ in paediatric ED patients triaged as having 'minor injuries not requiring a doctor' during lockdown [6]. Furthermore, a US study demonstrated increased high-severity ED attenders at triage during a state-

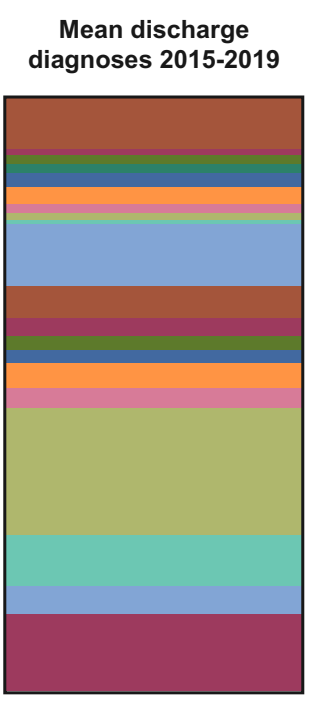

Total $=3706$

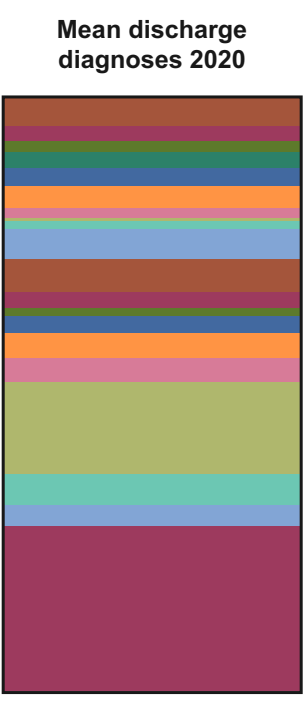

Total $=\mathbf{2 8 3 8}$

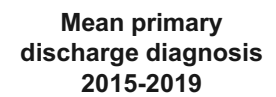

2015-2019

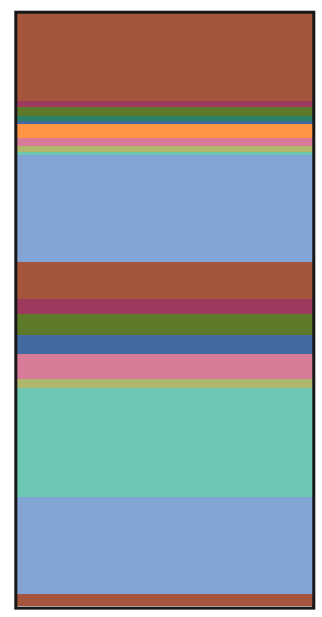

Total $=\mathbf{1 3 8 4 . 2}$
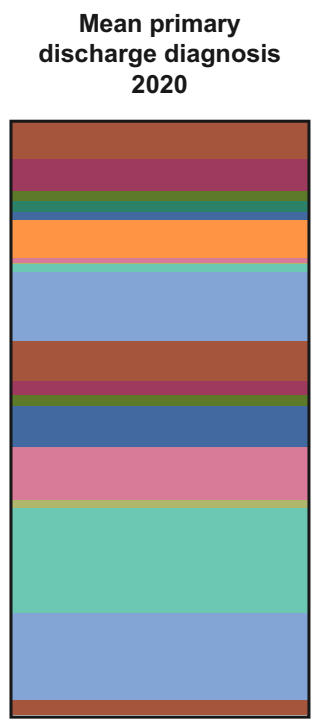

Total $=592$

Certain infectious and parasitic diseases

Neoplasms

Diseases of the blood and blood-forming organs and certain disorders involving the immune mechanism

Endocrine, nutritional and metabolic diseases

ㅁental, Behavioral and Neurodevelopmental disorders

D Diseases of the nervous system

Diseases of the eye and adnexa

$\square$ Diseases of the ear and mastoid process

$\square$ Diseases of the circulatory system

$\square$ Diseases of the respiratory system

Diseases of the digestive system

D Diseases of the skin and subcutaneous tissue

$\square$ Diseases of the musculoskeletal system and connective tissue

Diseases of the genitourinary system

$\square$ Certain conditions originating in the perinatal period

Congenital malformations, deformations and chromosomal abnormalities

- Symptoms, signs and abnormal clinical and laboratory findings, not elsewhere classified

$\square$ Injury, poisoning and certain other consequences of external causes

External causes of morbidity

Factors influencing health status and contact with health services

Fig. 3 Changes in relative proportions of diagnoses seen during the 2020 lockdown period. Differences in diagnoses by ICD-10 chapter headings for patients admitted during the first national lockdown period, compared to matched periods during the previous 5 years (2015-2019). Totals show mean numbers for the matched lockdown period (2015-2019) or total number for 2020. Shown for all diagnoses given on discharge (left panels) and 'primary' diagnosis only (right panels) 
Table 1 ICD-10 diagnoses with significant changes during lockdown assigned to broad diagnostic groups

\begin{tabular}{|c|c|c|c|c|c|}
\hline ICD-10 diagnosis & $\begin{array}{l}\text { Admissions } \\
\text { during lockdown } \\
\text { period: } 2015- \\
2019 \\
\text { Median (range) }\end{array}$ & $\begin{array}{l}\text { Admissions } \\
\text { during } \\
\text { lockdown } \\
\text { period: } 2020\end{array}$ & $\begin{array}{l}\text { Direction of change in } \\
\text { admissions in } 2020 \\
\text { (compared with } 2015- \\
\text { 2019) }\end{array}$ & $\begin{array}{l}\text { Absolute change during } \\
\text { lockdown compared to } \\
\text { median 2015-2019 }\end{array}$ & $P$ value* \\
\hline \multicolumn{6}{|l|}{ Infective illnesses } \\
\hline Viral infection, unspecified & $128(122-164)$ & 27 & $\downarrow$ & -101 & 0.0000 \\
\hline Acute tonsillitis, unspecified & $50(36-58)$ & 9 & $\downarrow$ & -41 & 0.0001 \\
\hline Acute upper respiratory infection, unspecified & $62(54-76)$ & 24 & $\downarrow$ & -38 & 0.0005 \\
\hline Unspecified acute lower respiratory infection & $54(44-59)$ & 22 & $\downarrow$ & -32 & 0.0007 \\
\hline Acute bronchiolitis, unspecified & $36(18-47)$ & 7 & $\downarrow$ & -29 & 0.0006 \\
\hline $\begin{array}{l}\text { Gastroenteritis and colitis of unspecified } \\
\text { origin }\end{array}$ & $46(42-56)$ & 18 & $\downarrow$ & -28 & 0.0009 \\
\hline Viral intestinal infection, unspecified & $22(6-30)$ & 1 & $\downarrow$ & -21 & 0.0004 \\
\hline Otitis media, unspecified & $21(10-32)$ & 5 & $\downarrow$ & -16 & 0.0046 \\
\hline Acute obstructive laryngitis (croup) & $17(14-28)$ & 1 & $\downarrow$ & -16 & 0.0002 \\
\hline Varicella without complication & $14(3-21)$ & 2 & $\downarrow$ & -12 & 0.0285 \\
\hline Lobar pneumonia, unspecified & $14(9-25)$ & 3 & $\downarrow$ & -11 & 0.0045 \\
\hline Conjunctivitis, unspecified & $8(4-10)$ & 1 & $\downarrow$ & -7 & 0.0072 \\
\hline Acute nasopharyngitis (common cold) & $6(4-27)$ & 0 & $\downarrow$ & -6 & 0.0075 \\
\hline $\begin{array}{l}\text { Meningitis in viral diseases classified } \\
\text { elsewhere }\end{array}$ & $5(1-11)$ & 0 & $\downarrow$ & -5 & 0.0476 \\
\hline Acute lymphadenitis of face, head and neck & $5(1-10)$ & 0 & $\downarrow$ & -5 & 0.0291 \\
\hline Enteroviral meningitis & $4(1-7)$ & 0 & $\downarrow$ & -4 & 0.0459 \\
\hline Other specified bacterial intestinal infections & $0(0-0)$ & 1 & $\uparrow$ & 1 & 0.0253 \\
\hline Whooping cough, unspecified & $0(0-0)$ & 1 & $\uparrow$ & 1 & 0.0253 \\
\hline Other infectious mononucleosis & $0(0-0)$ & 1 & $\uparrow$ & 1 & 0.0253 \\
\hline Enterovirus infection, unspecified site & $0(0-0)$ & 1 & $\uparrow$ & 1 & 0.0253 \\
\hline Echinococcosis, other and unspecified & $0(0-0)$ & 1 & $\uparrow$ & 1 & 0.0253 \\
\hline $\begin{array}{l}\text { Coronavirus as the cause of diseases classified } \\
\text { to other chapters }\end{array}$ & $0(0-0)$ & 1 & $\uparrow$ & 1 & 0.0253 \\
\hline Typhoid fever & $0(0-0)$ & 2 & $\uparrow$ & 2 & 0.0014 \\
\hline Salmonella enteritis & $0(0-0)$ & 2 & $\uparrow$ & 2 & 0.0014 \\
\hline Superficial mycosis, unspecified & $0(0-1)$ & 2 & $\uparrow$ & 2 & 0.0172 \\
\hline $\begin{array}{l}\text { Other specified bacterial agents as the cause of } \\
\text { diseases classified to other chapters }\end{array}$ & $2(1-5)$ & 6 & $\uparrow$ & 4 & 0.0285 \\
\hline Sepsis due to other Gram-negative organisms & $0(0-5)$ & 5 & $\uparrow$ & 5 & 0.0021 \\
\hline COVID-19, virus identified & $0(0-0)$ & 5 & $\uparrow$ & 5 & 0.0000 \\
\hline Total Infective illnesses & 494 & 148 & $\downarrow$ & -346 & $\mathrm{~N} / \mathrm{A}$ \\
\hline \multicolumn{6}{|l|}{ Likely sequelae of infective illness } \\
\hline Wheezing & $105(81-132)$ & 20 & $\downarrow$ & -85 & 0.0001 \\
\hline Nausea and vomiting & $91(69-129)$ & 37 & $\downarrow$ & -54 & 0.0003 \\
\hline Asthma, unspecified & $70(62-79)$ & 20 & $\downarrow$ & -50 & 0.0001 \\
\hline Fever, unspecified & $93(71-114)$ & 61 & $\downarrow$ & -32 & 0.0313 \\
\hline Rash and other nonspecific skin eruption & $36(31-51)$ & 13 & $\downarrow$ & -23 & 0.0006 \\
\hline Hypertrophy of tonsils & $12(4-34)$ & 2 & $\downarrow$ & -10 & 0.0102 \\
\hline Transient synovitis & $10(3-14)$ & 1 & $\downarrow$ & -9 & 0.0146 \\
\hline Mixed asthma & $0(0-0)$ & 1 & $\uparrow$ & 1 & 0.0253 \\
\hline Renal and perinephric abscess & $0(0-0)$ & 3 & $\uparrow$ & 3 & 0.0001 \\
\hline Total likely sequelae of infective illness & 417 & 158 & $\downarrow$ & -259 & $\mathrm{~N} / \mathrm{A}$ \\
\hline \multicolumn{6}{|l|}{ Accidental injury/poisoning } \\
\hline Fall involving playground equipment & $18(10-28)$ & 7 & $\downarrow$ & -11 & 0.0362 \\
\hline
\end{tabular}


Table 1 (continued)

\begin{tabular}{|c|c|c|c|c|c|}
\hline ICD-10 diagnosis & $\begin{array}{l}\text { Admissions } \\
\text { during lockdown } \\
\text { period: } 2015- \\
2019 \\
\text { Median (range) }\end{array}$ & $\begin{array}{l}\text { Admissions } \\
\text { during } \\
\text { lockdown } \\
\text { period: } 2020\end{array}$ & $\begin{array}{l}\text { Direction of change in } \\
\text { admissions in } 2020 \\
\text { (compared with } 2015- \\
\text { 2019) }\end{array}$ & $\begin{array}{l}\text { Absolute change during } \\
\text { lockdown compared to } \\
\text { median 2015-2019 }\end{array}$ & $P$ value* \\
\hline Unspecified injury of head & $11(7-25)$ & 2 & $\downarrow$ & -9 & 0.0069 \\
\hline Fracture of lower end of humerus & $10(4-14)$ & 3 & $\downarrow$ & -7 & 0.0203 \\
\hline Open wound of finger(s) with damage to nail & $8(3-11)$ & 1 & $\downarrow$ & -7 & 0.0099 \\
\hline Fracture of other finger & $8(4-12)$ & 1 & $\downarrow$ & -7 & 0.0064 \\
\hline $\begin{array}{l}\text { Caught, crushed, jammed or pinched in or } \\
\text { between objects }\end{array}$ & $8(7-11)$ & 1 & $\downarrow$ & -7 & 0.0039 \\
\hline Open wound of other parts of head & $8(5-14)$ & 2 & $\downarrow$ & -6 & 0.0324 \\
\hline $\begin{array}{l}\text { Foreign body entering into or through eye or } \\
\text { natural orifice }\end{array}$ & $8(6-9)$ & 2 & $\downarrow$ & -6 & 0.0086 \\
\hline Superficial injury of other parts of head & $9(7-20)$ & 4 & $\downarrow$ & -5 & 0.0390 \\
\hline Superficial injury of head, part unspecified & $5(2-10)$ & 0 & $\downarrow$ & -5 & 0.0376 \\
\hline Fall on and from stairs and steps & $5(3-7)$ & 0 & $\downarrow$ & -5 & 0.0037 \\
\hline Unspecified fall & $6(2-9)$ & 1 & $\downarrow$ & -5 & 0.0215 \\
\hline $\begin{array}{l}\text { Hit, struck, kicked, twisted, bitten or scratched } \\
\text { by another person }\end{array}$ & $5(3-7)$ & 0 & $\downarrow$ & -5 & 0.0220 \\
\hline $\begin{array}{l}\text { Fall involving ice-skates, skis, roller-skates or } \\
\text { skateboards }\end{array}$ & $3(2-8)$ & 0 & $\downarrow$ & -3 & 0.0284 \\
\hline Striking against or struck by sports equipment & $3(2-6)$ & 0 & $\downarrow$ & -3 & 0.0458 \\
\hline Striking against or struck by other objects & $5(5-10)$ & 2 & $\downarrow$ & -3 & 0.0382 \\
\hline Other injuries of eye and orbit & $0(0-0)$ & 1 & $\uparrow$ & 1 & 0.0253 \\
\hline $\begin{array}{l}\text { Multiple superficial injuries of shoulder and } \\
\text { upper arm }\end{array}$ & $0(0-0)$ & 1 & $\uparrow$ & 1 & 0.0253 \\
\hline $\begin{array}{l}\text { Multiple open wounds of shoulder and upper } \\
\text { arm }\end{array}$ & $0(0-0)$ & 1 & $\uparrow$ & 1 & 0.0253 \\
\hline Dislocation of radial head & $0(0-0)$ & 1 & $\uparrow$ & 1 & 0.0253 \\
\hline Sprain and strain of elbow & $0(0-0)$ & 1 & $\uparrow$ & 1 & 0.0253 \\
\hline Multiple superficial injuries of lower leg & $0(0-0)$ & 1 & $\uparrow$ & 1 & 0.0253 \\
\hline Other specified injuries of lower leg & $0(0-0)$ & 1 & $\uparrow$ & 1 & 0.0253 \\
\hline $\begin{array}{l}\text { Unspecified injury of lower limb, level } \\
\text { unspecified }\end{array}$ & $0(0-0)$ & 1 & $\uparrow$ & 1 & 0.0253 \\
\hline Poisoning: Benzodiazepines & $0(0-0)$ & 1 & $\uparrow$ & 1 & 0.0253 \\
\hline $\begin{array}{l}\text { Poisoning: Local antifungal, anti-infective } \\
\text { and anti-inflammatory drugs, not elsewhere } \\
\text { classified }\end{array}$ & $0(0-0)$ & 1 & $\uparrow$ & 1 & 0.0253 \\
\hline $\begin{array}{l}\text { Contact with other powered hand tools and } \\
\text { household machinery }\end{array}$ & $0(0-0)$ & 1 & $\uparrow$ & 1 & 0.0253 \\
\hline $\begin{array}{l}\text { Discharge from other and unspecified } \\
\text { firearms }\end{array}$ & $0(0-0)$ & 1 & $\uparrow$ & 1 & 0.0253 \\
\hline Multiple superficial injuries of forearm & $0(0-1)$ & 2 & $\uparrow$ & 2 & 0.0172 \\
\hline Toxic effect of soaps and detergents & $0(0-1)$ & 2 & $\uparrow$ & 2 & 0.0172 \\
\hline $\begin{array}{l}\text { Inhalation and ingestion of food causing } \\
\text { obstruction of respiratory tract }\end{array}$ & $0(0-1)$ & 2 & $\uparrow$ & 2 & 0.0172 \\
\hline Other specified injuries of hip and thigh & $0(0-0)$ & 3 & $\uparrow$ & 3 & 0.0001 \\
\hline Total accidental injury/poisoning & 120 & 47 & $\downarrow$ & -73 & N/A \\
\hline \multicolumn{6}{|l|}{ Non-specific pains, aches, malaise } \\
\hline Other and unspecified abdominal pain & $35(25-51)$ & 7 & $\downarrow$ & -28 & 0.0003 \\
\hline Headache & $27(24-30)$ & 8 & $\downarrow$ & -19 & 0.0009 \\
\hline Pain in joint & $16(10-20)$ & 3 & $\downarrow$ & -13 & 0.0011 \\
\hline Malaise and fatigue & $17(10-19)$ & 6 & $\downarrow$ & -11 & 0.0334 \\
\hline Pain in limb & $7(6-11)$ & 1 & $\downarrow$ & -6 & 0.0032 \\
\hline
\end{tabular}


Table 1 (continued)

\begin{tabular}{|c|c|c|c|c|c|}
\hline ICD-10 diagnosis & $\begin{array}{l}\text { Admissions } \\
\text { during lockdown } \\
\text { period: } 2015- \\
2019 \\
\text { Median (range) }\end{array}$ & $\begin{array}{l}\text { Admissions } \\
\text { during } \\
\text { lockdown } \\
\text { period: } 2020\end{array}$ & $\begin{array}{l}\text { Direction of change in } \\
\text { admissions in } 2020 \\
\text { (compared with } 2015- \\
\text { 2019) }\end{array}$ & $\begin{array}{l}\text { Absolute change during } \\
\text { lockdown compared to } \\
\text { median 2015-2019 }\end{array}$ & $P$ value* \\
\hline Pain localized to upper abdomen & $3(2-7)$ & 0 & $\downarrow$ & -3 & 0.0356 \\
\hline $\begin{array}{l}\text { Other symptoms and signs concerning food } \\
\text { and fluid intake }\end{array}$ & $3(0-14)$ & 0 & $\downarrow$ & -3 & 0.0293 \\
\hline Total Non-specific pains, aches, malaise & 108 & 25 & $\downarrow$ & -83 & N/A \\
\hline \multicolumn{6}{|l|}{ Likely related to pandemic screening } \\
\hline $\begin{array}{l}\text { Observation for other suspected diseases and } \\
\text { conditions }\end{array}$ & $9(7-15)$ & 97 & $\uparrow$ & 88 & 0.0000 \\
\hline $\begin{array}{l}\text { Special screening examination for other viral } \\
\text { diseases }\end{array}$ & $0(0-0)$ & 47 & $\uparrow$ & 47 & 0.0000 \\
\hline Total likely related to pandemic screening & 9 & 144 & $\uparrow$ & 135 & N/A \\
\hline \multicolumn{6}{|l|}{ Likely incidental finding or co-morbidity } \\
\hline $\begin{array}{l}\text { Personal history of allergy, other than to drugs } \\
\text { and biological substances }\end{array}$ & $8(2-38)$ & 25 & $\uparrow$ & 17 & 0.0203 \\
\hline $\begin{array}{l}\text { Family history of diseases of the respiratory } \\
\text { system }\end{array}$ & $1(0-4)$ & 17 & $\uparrow$ & 16 & 0.0000 \\
\hline $\begin{array}{l}\text { Personal history of long-term (current) use of } \\
\text { other medicaments }\end{array}$ & $5(1-8)$ & 17 & $\uparrow$ & 12 & 0.0001 \\
\hline Cardiac murmur, unspecified & $8(1-13)$ & 19 & $\uparrow$ & 11 & 0.0280 \\
\hline Family history of diabetes mellitus & $3(1-7)$ & 14 & $\uparrow$ & 11 & 0.0111 \\
\hline Personal history of irradiation & $0(0-2)$ & 10 & $\uparrow$ & 10 & 0.0001 \\
\hline Other transplanted organ and tissue status & $1(0-5)$ & 11 & $\uparrow$ & 10 & 0.0029 \\
\hline $\begin{array}{l}\text { Personal history of major surgery, not } \\
\text { elsewhere classified }\end{array}$ & $19(13-21)$ & 28 & $\uparrow$ & 9 & 0.0404 \\
\hline $\begin{array}{l}\text { Family history of other endocrine, nutritional } \\
\text { and metabolic diseases }\end{array}$ & $1(0-2)$ & 9 & $\uparrow$ & 8 & 0.0014 \\
\hline $\begin{array}{l}\text { Personal history of chemotherapy for } \\
\text { neoplastic disease }\end{array}$ & $4(2-7)$ & 12 & $\uparrow$ & 8 & 0.0091 \\
\hline $\begin{array}{l}\text { Family history of diseases of the skin and } \\
\text { subcutaneous tissue }\end{array}$ & $1(0-5)$ & 8 & $\uparrow$ & 7 & 0.0036 \\
\hline Acidosis & $7(2-9)$ & 13 & $\uparrow$ & 6 & 0.0064 \\
\hline $\begin{array}{l}\text { Family history of other diseases of the } \\
\text { genitourinary system }\end{array}$ & $0(0-5)$ & 6 & $\uparrow$ & 6 & 0.0020 \\
\hline $\begin{array}{l}\text { Personal history of allergy to other antibiotic } \\
\text { agents }\end{array}$ & $1(1-5)$ & 7 & $\uparrow$ & 6 & 0.0087 \\
\hline $\begin{array}{l}\text { Personal history of allergy to other drugs, } \\
\text { medicaments and biological substances }\end{array}$ & $5(0-10)$ & 11 & $\uparrow$ & 6 & 0.0118 \\
\hline $\begin{array}{l}\text { Family history of other infectious and } \\
\text { parasitic diseases }\end{array}$ & $1(0-3)$ & 6 & $\uparrow$ & 5 & 0.0043 \\
\hline Family history of other specified conditions & $0(0-1)$ & 5 & $\uparrow$ & 5 & 0.0009 \\
\hline $\begin{array}{l}\text { Personal history of endocrine, nutritional and } \\
\text { metabolic diseases }\end{array}$ & $0(0-2)$ & 5 & $\uparrow$ & 5 & 0.0001 \\
\hline Acquired absence of genital organ(s) & $0(0-2)$ & 5 & $\uparrow$ & 5 & 0.0156 \\
\hline Haemangioma, any site & $3(1-4)$ & 6 & $\uparrow$ & 3 & 0.0313 \\
\hline $\begin{array}{l}\text { Abnormal results of cardiovascular function } \\
\text { studies }\end{array}$ & $0(0-0)$ & 3 & $\uparrow$ & 3 & 0.0014 \\
\hline $\begin{array}{l}\text { Personal history of diseases of the blood and } \\
\text { blood-forming organs and certain disorders } \\
\text { involving the immune mechanism }\end{array}$ & $0(0-2)$ & 3 & $\uparrow$ & 3 & 0.0062 \\
\hline Personal history of allergy to analgesic agent & $0(0-1)$ & 3 & $\uparrow$ & 3 & 0.0062 \\
\hline Family history of eye and ear disorders & $0(0-1)$ & 2 & $\uparrow$ & 2 & 0.0172 \\
\hline Personal history of other specified conditions & $0(0-1)$ & 2 & $\uparrow$ & 2 & 0.0172 \\
\hline Personal history of allergy to anaesthetic agent & $0(0-0)$ & 2 & $\uparrow$ & 2 & 0.0014 \\
\hline Personal history of allergy to narcotic agent & $0(0-0)$ & 2 & $\uparrow$ & 2 & 0.0014 \\
\hline
\end{tabular}


Table 1 (continued)

\begin{tabular}{|c|c|c|c|c|c|}
\hline ICD-10 diagnosis & $\begin{array}{l}\text { Admissions } \\
\text { during lockdown } \\
\text { period: } 2015- \\
2019 \\
\text { Median (range) }\end{array}$ & $\begin{array}{l}\text { Admissions } \\
\text { during } \\
\text { lockdown } \\
\text { period: } 2020\end{array}$ & $\begin{array}{l}\text { Direction of change in } \\
\text { admissions in } 2020 \\
\text { (compared with } 2015- \\
2019 \text { ) }\end{array}$ & $\begin{array}{l}\text { Absolute change during } \\
\text { lockdown compared to } \\
\text { median 2015-2019 }\end{array}$ & $P$ value* \\
\hline Acquired absence of other organs & $0(0-0)$ & 2 & $\uparrow$ & 2 & 0.0014 \\
\hline $\begin{array}{l}\text { Abnormal findings on diagnostic imaging of } \\
\text { liver and biliary tract }\end{array}$ & $0(0-0)$ & 1 & $\uparrow$ & 1 & 0.0253 \\
\hline Total likely co-morbidity or incidental finding & 68 & 254 & $\uparrow$ & 186 & N/A \\
\hline \multicolumn{6}{|l|}{ Other diagnoses } \\
\hline Psychotherapy, not elsewhere classified & $0(0-15)$ & 12 & $\uparrow$ & 12 & 0.0006 \\
\hline Essential (primary) hypertension & $1(0-3)$ & 11 & $\uparrow$ & 10 & 0.0002 \\
\hline Dietary counselling and surveillance & $1(0-5)$ & 11 & $\uparrow$ & 10 & 0.0002 \\
\hline Strabismus, unspecified & $1(0-4)$ & 9 & $\uparrow$ & 8 & 0.0058 \\
\hline Malignant neoplasm: Cerebellum & $0(0-1)$ & 7 & $\uparrow$ & 7 & 0.0000 \\
\hline Acute renal failure, unspecified & $1(1-3)$ & 8 & $\uparrow$ & 7 & 0.0172 \\
\hline Other specified diabetes mellitus & $0(0-1)$ & 6 & $\uparrow$ & 6 & 0.0036 \\
\hline Myopathy, unspecified & $0(0-0)$ & 6 & $\uparrow$ & 6 & 0.0001 \\
\hline Unspecified appendicitis & $1(0-5)$ & 7 & $\uparrow$ & 6 & 0.0007 \\
\hline Glucocorticoids and synthetic analogues & $0(0-0)$ & 6 & $\uparrow$ & 6 & 0.0001 \\
\hline Bradycardia, unspecified & $3(1-5)$ & 8 & $\uparrow$ & 5 & 0.0063 \\
\hline Combined immunodeficiency, unspecified & $0(0-4)$ & 4 & $\uparrow$ & 4 & 0.0346 \\
\hline Atopic dermatitis, unspecified & $0(0-1)$ & 4 & $\uparrow$ & 4 & 0.0140 \\
\hline $\begin{array}{l}\text { Other specified disorders of male genital } \\
\text { organs }\end{array}$ & $2(0-4)$ & 6 & $\uparrow$ & 4 & 0.0464 \\
\hline $\begin{array}{l}\text { Other specified congenital malformations of } \\
\text { heart }\end{array}$ & $0(0-1)$ & 4 & $\uparrow$ & 4 & 0.0001 \\
\hline Congenital hydronephrosis & $1(0-2)$ & 5 & $\uparrow$ & 4 & 0.0328 \\
\hline $\begin{array}{l}\text { Follow-up examination after unspecified } \\
\text { treatment for other conditions }\end{array}$ & $0(0-3)$ & 4 & $\uparrow$ & 4 & 0.0069 \\
\hline $\begin{array}{l}\text { Malignant neoplasm of other and ill-defined } \\
\text { sites: Abdomen }\end{array}$ & $0(0-4)$ & 3 & $\uparrow$ & 3 & 0.0244 \\
\hline Secondary malignant neoplasm of lung & $2(0-2)$ & 5 & $\uparrow$ & 3 & 0.0047 \\
\hline $\begin{array}{l}\text { Other and unspecified adrenocortical } \\
\text { insufficiency }\end{array}$ & $1(0-3)$ & 4 & $\uparrow$ & 3 & 0.0075 \\
\hline Obsessive-compulsive disorder, unspecified & $0(0-3)$ & 3 & $\uparrow$ & 3 & 0.0244 \\
\hline Polyneuropathy, unspecified & $0(0-0)$ & 3 & $\uparrow$ & 3 & 0.0001 \\
\hline Pre-excitation syndrome & $0(0-0)$ & 3 & $\uparrow$ & 3 & 0.0001 \\
\hline $\begin{array}{l}\text { Other specified disorders of nose and nasal } \\
\text { sinuses }\end{array}$ & $0(0-1)$ & 3 & $\uparrow$ & 3 & 0.0156 \\
\hline Chronic periodontitis & $0(0-0)$ & 3 & $\uparrow$ & 3 & 0.0014 \\
\hline Congenital absence of ovary & $0(0-0)$ & 3 & $\uparrow$ & 3 & 0.0001 \\
\hline Undescended testicle, bilateral & $0(0-1)$ & 3 & $\uparrow$ & 3 & 0.0011 \\
\hline Ataxic gait & $0(0-1)$ & 3 & $\uparrow$ & 3 & 0.0156 \\
\hline $\begin{array}{l}\text { Other complications of procedures, not } \\
\text { elsewhere classified }\end{array}$ & $0(0-1)$ & 3 & $\uparrow$ & 3 & 0.0062 \\
\hline $\begin{array}{l}\text { Malignant neoplasm: Connective and soft } \\
\text { tissue of head, face and neck }\end{array}$ & $0(0-0)$ & 2 & $\uparrow$ & 2 & 0.0014 \\
\hline Malignant neoplasm: Spinal cord & $0(0-0)$ & 2 & $\uparrow$ & 2 & 0.0014 \\
\hline $\begin{array}{l}\text { Secondary malignant neoplasm of brain and } \\
\text { cerebral meninges }\end{array}$ & $0(0-0)$ & 2 & $\uparrow$ & 2 & 0.0014 \\
\hline Other adrenocortical overactivity & $0(0-0)$ & 2 & $\uparrow$ & 2 & 0.0253 \\
\hline Tic disorder, unspecified & $0(0-0)$ & 2 & $\uparrow$ & 2 & 0.0014 \\
\hline Spinal muscular atrophy, unspecified & $0(0-2)$ & 2 & $\uparrow$ & 2 & 0.0211 \\
\hline Syringomyelia and syringobulbia & $0(0-1)$ & 2 & $\uparrow$ & 2 & 0.0172 \\
\hline
\end{tabular}


Table 1 (continued)

\begin{tabular}{|c|c|c|c|c|c|}
\hline ICD-10 diagnosis & $\begin{array}{l}\text { Admissions } \\
\text { during lockdown } \\
\text { period: } 2015- \\
2019 \\
\text { Median (range) }\end{array}$ & $\begin{array}{l}\text { Admissions } \\
\text { during } \\
\text { lockdown } \\
\text { period: } 2020\end{array}$ & $\begin{array}{l}\text { Direction of change in } \\
\text { admissions in } 2020 \\
\text { (compared with } 2015- \\
2019 \text { ) }\end{array}$ & $\begin{array}{l}\text { Absolute change during } \\
\text { lockdown compared to } \\
\text { median 2015-2019 }\end{array}$ & $P$ value* \\
\hline Other specified diseases of spinal cord & $0(0-0)$ & 2 & $\uparrow$ & 2 & 0.0014 \\
\hline Intracerebral haemorrhage, intraventricular & $0(0-0)$ & 2 & $\uparrow$ & 2 & 0.0014 \\
\hline $\begin{array}{l}\text { Respiratory failure, unspecified - Type un- } \\
\text { specified }\end{array}$ & $0(0-0)$ & 2 & $\uparrow$ & 2 & 0.0014 \\
\hline Pilonidal cyst without abscess & $0(0-1)$ & 2 & $\uparrow$ & 2 & 0.0172 \\
\hline Acne, unspecified & $0(0-1)$ & 2 & $\uparrow$ & 2 & 0.0172 \\
\hline $\begin{array}{l}\text { Other specified intervertebral disc } \\
\text { displacement }\end{array}$ & $0(0-0)$ & 2 & $\uparrow$ & 2 & 0.0014 \\
\hline Neuralgia and neuritis, unspecified & $0(0-0)$ & 2 & $\uparrow$ & 2 & 0.0014 \\
\hline Other specified disorders of kidney and ureter & $2(0-3)$ & 4 & $\uparrow$ & 2 & 0.0408 \\
\hline Disorder of male genital organs, unspecified & $0(0-0)$ & 2 & $\uparrow$ & 2 & 0.0014 \\
\hline $\begin{array}{l}\text { Other specified congenital malformations of } \\
\text { brain }\end{array}$ & $1(0-2)$ & 3 & $\uparrow$ & 2 & 0.0442 \\
\hline Cervical spina bifida with hydrocephalus & $0(0-0)$ & 2 & $\uparrow$ & 2 & 0.0014 \\
\hline Cleft soft palate & $0(0-0)$ & 2 & $\uparrow$ & 2 & 0.0253 \\
\hline Hypospadias, balanic & $0(0-0)$ & 2 & $\uparrow$ & 2 & 0.0014 \\
\hline Haemoptysis & $0(0-1)$ & 2 & $\uparrow$ & 2 & 0.0172 \\
\hline Ataxia, unspecified & $0(0-1)$ & 2 & $\uparrow$ & 2 & 0.0172 \\
\hline Hyperglycaemia, unspecified & $0(0-1)$ & 2 & $\uparrow$ & 2 & 0.0172 \\
\hline Glycosuria & $0(0-0)$ & 2 & $\uparrow$ & 2 & 0.0014 \\
\hline Removal from home in childhood & $0(0-0)$ & 2 & $\uparrow$ & 2 & 0.0253 \\
\hline $\begin{array}{l}\text { Diagnoses occurring only once in } 2020 n= \\
63^{* *}\end{array}$ & $0(0-0)$ & 1 & $\uparrow$ & 63 & 0.0253 \\
\hline Other specified soft tissue disorders & $4(1-6)$ & 0 & $\downarrow$ & -4 & 0.0450 \\
\hline $\begin{array}{l}\text { Neuromuscular dysfunction of bladder, } \\
\text { unspecified }\end{array}$ & $4(2-10)$ & 0 & $\downarrow$ & -4 & 0.0166 \\
\hline Retention of urine & $4(3-9)$ & 0 & $\downarrow$ & -4 & 0.0224 \\
\hline Intentional self-harm by sharp object & $4(0-9)$ & 0 & $\downarrow$ & -4 & 0.0285 \\
\hline Hypoglycaemia, unspecified & $8(6-17)$ & 3 & $\downarrow$ & -5 & 0.0150 \\
\hline Cerebral palsy, unspecified & $5(4-7)$ & 0 & $\downarrow$ & -5 & 0.0124 \\
\hline Down's syndrome, unspecified & $7(3-10)$ & 2 & $\downarrow$ & -5 & 0.0405 \\
\hline $\begin{array}{l}\text { Haemorrhage and haematoma complicating a } \\
\text { procedure, not elsewhere classified }\end{array}$ & $8(6-12)$ & 1 & $\downarrow$ & -7 & 0.0195 \\
\hline Removal of other organ (partial) (total) & $9(8-13)$ & 2 & $\downarrow$ & -7 & 0.0095 \\
\hline Anorexia & $10(1-30)$ & 1 & $\downarrow$ & -9 & 0.0048 \\
\hline Other and unspecified convulsions & $20(14-40)$ & 10 & $\downarrow$ & -10 & 0.0254 \\
\hline Spontaneous ecchymoses & $32(22-36)$ & 2 & $\downarrow$ & -30 & 0.0001 \\
\hline Total other diagnoses & 132 & 294 & $\uparrow$ & 162 & N/A \\
\hline
\end{tabular}

Table of changes in numbers of admissions between the first national lockdown period in 2020 and matched period during the previous years for differences which reached significance $(p<0.05)$. Diagnoses are divided into categories of infective illnesses, likely sequelae of infective illness, accidental injury, nonspecific pains/aches/malaise, likely related to pandemic screening, likely incidental finding, or co-morbidity and other diagnoses. $* P$ value calculated using admissions per week with given diagnosis for the 7 weeks of lockdown (2020) or the matched 7 weeks in each of 2015-2019 ( $n$ $=35$ weeks). $P$ values represent independent-samples Kruskal-Wallis test, controlled for multiple comparisons with stepwise step-down. $P<0.05$ were taken as significant and are highlighted in bold. **Diagnoses which occurred only once (all in 2020) were redacted for clarity; these are all fully stated in supplemental table $3, n=63$ individual diagnoses met this category

wide stay-at-home period compared to the previous 3 years [12], suggesting low severity patients were kept at home. A small proportion of children may have not been brought to hospital due to documented anxieties surrounding hospital attendance during the pandemic [26], although current evidence suggests this group is small or negligible [27]. 
A

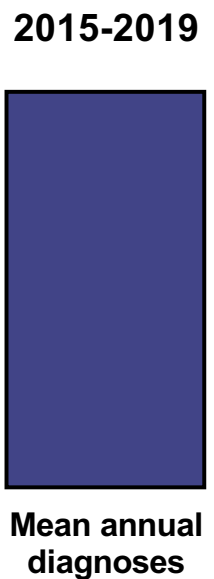

Total $=3569.8$
2020

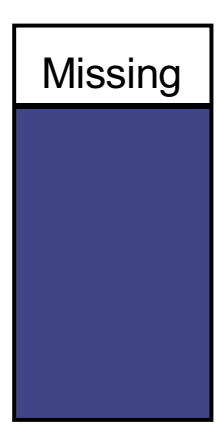

2020
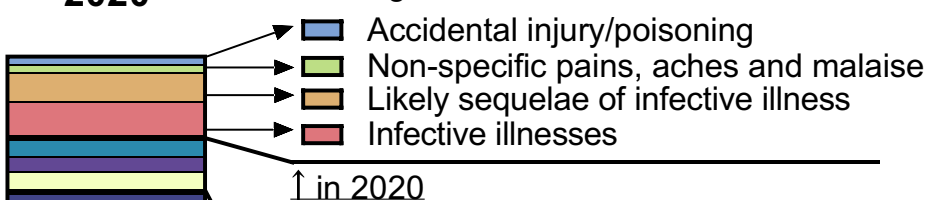

$\left\{\begin{array}{l}\frac{\uparrow \text { in } 2020}{\square \text { Other diagnoses }} \\ \square \text { Oikely related to }\end{array}\right.$

$\square$ Likely related to pandemic screening $\square$ Likely incidental finding or co-morbidity

B

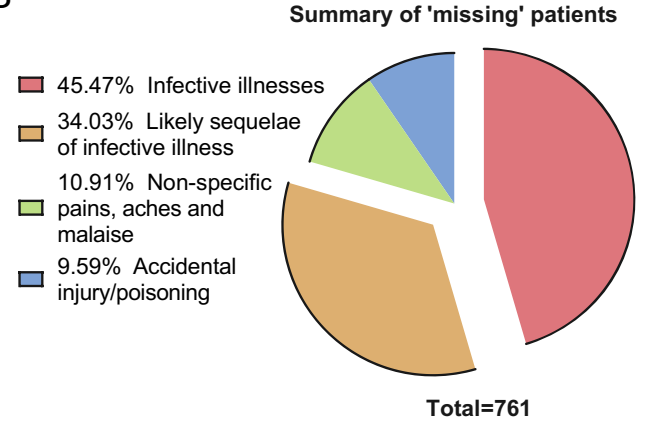

D

Likely sequelae of infective illness
C

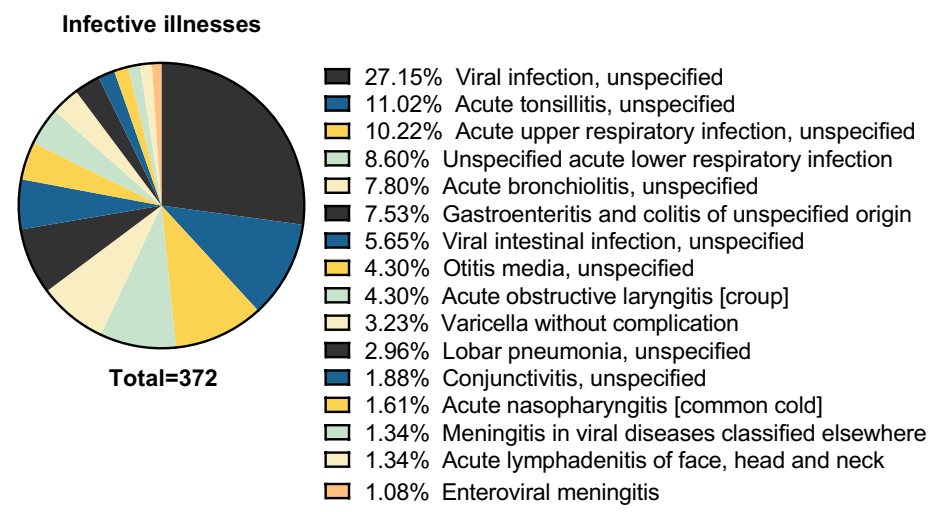

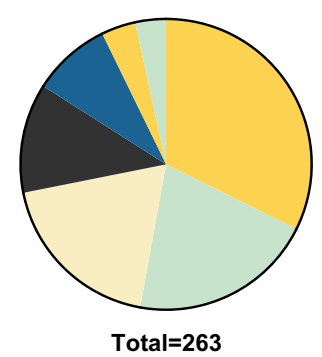

Total $=\mathbf{2 6 3}$

Fig. 4 Comparing diagnoses made in 2015-2019 to 2020, identifies 'missing' diagnoses of the first UK lockdown. The 'missing' patients are shown (white bar) as difference in mean annual diagnoses examined in 2015-2019 (A-left panel), against all diagnoses made in 2020 (Amiddle panel). All ICD-10 diagnoses during the first national lockdown period in 2020 and matched dates in 2015-2019 are shown only where the diagnosis occurred annually (mean $\geq 1$ ) in 2015-2019, or at least once in $2020, n=1117$ ICD-10 codes. Net changes for diagnostic groups with

Reassuringly, a national study across Scotland found no difference in childhood inpatient mortality during lockdown, compared to the previous four years [14]. Therefore, reductions in infectious disease-related admissions likely result from (1) reduced infectious disease burden due to COVID19 public health measures, (2) tolerating/monitoring children significant increases in diagnoses in 2020 and decreases ('missing') in 2020 are shown (A-right panel). The breakdown of 'missing' diagnoses (groups with a net significant decrease in diagnoses during the first 2020 lockdown period compared to 2015-2019) are shown by assigned group (B). The proportions of individual diagnoses which had a net decrease are shown amongst infective illnesses $(\mathbf{C})$ and likely sequelae of infective illness (D)

with mild and self-limiting illness at home due to greater parental supervision whilst locked down and/or information campaigns to avoid unnecessary healthcare utilisation, and (3) healthcare anxieties during the COVID-19 pandemic.

Non-specific pains/aches/malaise were significantly reduced during lockdown, many of which are likely benign 
and self-limiting. An Italian study also demonstrated significant reductions of children brought to ED with pain during lockdown [10]. We reiterate these authors' concern that a proportion of these non-attenders may have concerning or red flag features, including safeguarding concerns.

Increased parental supervision, school closures, fewer opportunities for sports, and playground closures may account for the $9.6 \%$ reduction in accidental injuries/poisonings. Findings internationally support the reductions of all fractures $[11,28,29]$, accidental injuries/poisoning [5, 8], and burns [30] during lockdowns. Our data corroborated a decrease in superficial injuries and lacerations, fractures, falls, and accidental poisoning, with a $74.5 \%$ reduction in childhood injuries. It remains of concern that some children who sustain injuries are not brought to medical attention but may later transpire to be more serious, requiring social/forensic or safeguarding investigations.

\section{Recommendations}

We propose communication pathways which

(1) Establish the duration and nature of symptom morbidity, and level of parent/carer anxiety, prior to patients attending for emergency care, to provide feedback and reinforce health education;

(2) Improve the immediacy of 'telemed' health advice, empowering parents/carers in managing mild and selflimiting illnesses at home;

(3) Promote health information for parents/carers of children of all ages, including raising awareness of red flag symptoms, and alleviating healthcare anxieties throughout the pandemic.

\section{Conclusions}

Oxfordshire paediatric ED attendances and hospital admissions were markedly reduced by up to $62 \%$ during the first 2020 lockdown. By controlling for the activity within one region and using five historical years, our data encompasses the use of steady demographics and natural behaviours of the population when utilising emergency services over the 6-year study period, and better controls for year-to-year fluctuations.

By using hypothesis-independent standardised ICD-10 diagnostic codes, our findings demonstrate infectious diseases, or their sequelae, account for the majority ( $80 \%$ ) of reductions in paediatric inpatients during lockdown. This is likely driven by reductions in infectious disease transmission due to public health measures. A further $20 \%$ of 'missing' diagnoses were accidental injuries/poisonings or non-specific pains/aches/ malaise. We postulate that some 'missing' presentations may represent patients with concerning or evolving conditions, safeguarding concerns, and require attention but did not present to healthcare services. Hence, we emphasise that some children with concerning features of physical, social emotional, or mental illness may be missed.

Supplementary Information The online version contains supplementary material available at https://doi.org/10.1007/s00431-021-04123-x.

Acknowledgements We are extremely grateful to the IM\&T department (Oxford University Hospitals), particularly Laura Aylott and Carl Rogers, who extracted the admissions and ED data, respectively. We thank Dr Justin Sims (Clinical Lead for Paediatrics, Horton General Hospital, Banbury) for helpful input and encouragement in establishing this project. We are grateful for Dr Chantal Hargreaves for reviewing this manuscript. We thank Mark Beswick at the UK Met Office National Meteorological Archive for providing historical pollen count data.

Authors' contributions JEGC conceived and designed the study, collated and analysed the data, generated the figures/tables, drafted the manuscript, and revised the manuscript. RB assisted with study design and data analysis, revised, and critically reviewed the manuscript. RP provided senior speciality input, revised, and critically reviewed the manuscript. All authors verify the underlying data used for analysis. All authors approved the final manuscript.

Data Availability Raw data from this study can be made available to interested parties on request. All data sharing requests will require approval from Oxford University Hospitals NHS Foundation Trust prior to release. Data screening will be required prior to release, to ensure no individual patient can be identified.

\section{Declarations}

Ethics approval/Consent to participate/Consent for publication Data was gathered for clinical audit purposes following the first national lockdown. Trust procedures were followed for access to anonymised patient data, completed in May 2020. This study does not meet criteria set out by the NHS Health Research Authority for requiring research ethics committee review and approval.

Conflict of interest The authors declare no competing interests.

Abbreviations CNS, Central nervous system; COVID-19, Coronavirus Disease 2019; ED, Emergency Department; ICD-10, International Statistical Classification of Diseases and related health problems 10; LOS, Length of stay; SARS-CoV-2, Severe Acute Respiratory Syndrome Coronavirus 2; UK, United Kingdom; US, United States; USA, United States of America

\section{References}

1. Timeline of the COVID-19 pandemic in the United Kingdom (2020) Wikipedia. 2020. https://en.wikipedia.org/w/index.php? title=Timeline_of_the_COVID-19_pandemic_in the_United Kingdom_(January\%E2\%80\%93June_2020)\&oldid=994757237. Accessed 18 Dec 2020 
2. Bressan S, Gallo E, Tirelli F et al (2020) Lockdown: more domestic accidents than COVID-19 in children. Arch Dis Child. https://doi. org/10.1136/archdischild-2020-319547

3. Isba R, Edge R, Jenner R et al (2020) Where have all the children gone? Decreases in paediatric emergency department attendances at the start of the COVID-19 pandemic of 2020. Arch Dis Child 105: 704. https://doi.org/10.1136/archdischild-2020-319385

4. Lazzerini M, Barbi E, Apicella A et al (2020) Delayed access or provision of care in Italy resulting from fear of COVID-19. Lancet Child Adolesc Health 4:e10-e11. https://doi.org/10.1016/S23524642(20)30108-5

5. Dopfer C, Wetzke M, Zychlinsky Scharff A et al (2020) COVID-19 related reduction in pediatric emergency healthcare utilization - a concerning trend. BMC Pediatr 20:427. https://doi.org/10.1186/ s12887-020-02303-6

6. Scaramuzza A, Tagliaferri F, Bonetti L et al (2020) Changing admission patterns in paediatric emergency departments during the COVID-19 pandemic. Arch Dis Child 105:704-706. https://doi. org/10.1136/archdischild-2020-319397

7. Akuaake LM, Hendrikse C, Spittal G et al (2020) Cross-sectional study of paediatric case mix presenting to an emergency centre in Cape Town, South Africa, during COVID-19. bmjpo 4:e000801. https://doi.org/10.1136/bmjpo-2020-000801

8. Dann L, Fitzsimons J, Gorman KM et al (2020) Disappearing act: COVID-19 and paediatric emergency department attendances. Arch Dis Child 105:810-811. https://doi.org/10.1136/ archdischild-2020-319654

9. Ciofidegli Atti ML, Campana A, Muda AO et al (2020) Facing SARS-CoV-2 Pandemic at a COVID-19 Regional Children's Hospital in Italy. Pediatr Infect Dis J Publish Ahead of Print. https://doi.org/10.1097/INF.0000000000002811

10. Silvagni D, Milani GP, Benini F (2020; Publish Ahead of Print) Children and the use of emergency departments during the COVID-19 pandemic: where did the pain end up? Pediatr Emerg Care. https://doi.org/10.1097/PEC.0000000000002256

11. Goldman RD, Grafstein E, Barclay N et al (2020) Paediatric patients seen in 18 emergency departments during the COVID-19 pandemic. Emerg Med J. https://doi.org/10.1136/emermed-2020210273

12. Chaiyachati BH, Agawu A, Zorc JJ et al (2020) Trends in pediatric emergency department utilization after institution of coronavirus disease-19 mandatory social distancing. J Pediatr 226:274277.e1. https://doi.org/10.1016/j.jpeds.2020.07.048

13. Chong S-L, Soo JSL, Allen JC et al (2020) Impact of COVID-19 on pediatric emergencies and hospitalizations in Singapore. BMC Pediatr 20:562. https://doi.org/10.1186/s12887-020-02469-z

14. Williams TC, MacRae C, Swann OV et al (2021) Indirect effects of the COVID-19 pandemic on paediatric healthcare use and severe disease: a retrospective national cohort study. Arch Dis Child. https://doi.org/10.1136/archdischild-2020-321008

15. Bhopal S, Buckland A, McCrone R et al (2020) Who has been missed? Dramatic decrease in numbers of children seen for child protection assessments during the pandemic. Arch Dis Child. https://doi.org/10.1136/archdischild-2020-319783

16. Caron F, Plancq M-C, Tourneux P et al (2020) Was child abuse underdetected during the COVID-19 lockdown? Arch Pediatr 27: 399-400. https://doi.org/10.1016/j.arcped.2020.07.010
17. Munro APS, Faust SN (2020) COVID-19 in children: current evidence and key questions. Curr Opin Infect Dis 33:540-547. https:// doi.org/10.1097/QCO.0000000000000690

18. Van Brusselen D, De Troeyer K, ter Haar E et al (2021) Bronchiolitis in COVID-19 times: a nearly absent disease? Eur J Pediatr. https://doi.org/10.1007/s00431-021-03968-6

19. Angoulvant F, Ouldali N, Yang DD et al (2021) Coronavirus disease 2019 pandemic: impact caused by school closure and national lockdown on pediatric visits and admissions for viral and nonviral infections - a time series analysis. Clin Infect Dis 72:319-322. https://doi.org/10.1093/cid/ciaa710

20. Gern JE, Busse WW (2002) Relationship of viral infections to wheezing illnesses and asthma. Nat Rev Immunol 2:132-138. https://doi.org/10.1038/nri725

21. Jartti T, Gern JE (2017) Role of viral infections in the development and exacerbation of asthma in children. J Allergy Clin Immunol 140:895-906. https://doi.org/10.1016/j.jaci.2017.08.003

22. Esposito S, Galeone C, Lelii M et al (2014) Impact of air pollution on respiratory diseases in children with recurrent wheezing or asthma. BMC Pulm Med 14:130. https://doi.org/10.1186/1471-2466$14-130$

23. Anderson HR, Favarato G, Atkinson RW (2013) Long-term exposure to air pollution and the incidence of asthma: meta-analysis of cohort studies. Air Qual Atmos Health 6:47-56. https://doi.org/10. 1007/s11869-011-0144-5

24. Ropkins K, Tate JE (2021) Early observations on the impact of the COVID-19 lockdown on air quality trends across the UK. Sci Total Environ 754:142374. https://doi.org/10.1016/j.scitotenv.2020. 142374

25. Menut L, Bessagnet B, Siour G et al (2020) Impact of lockdown measures to combat Covid-19 on air quality over western Europe. Sci Total Environ 741:140426. https://doi.org/10.1016/j.scitotenv. 2020.140426

26. Nicholson E, McDonnell T, Conlon C et al (2020) Parental hesitancy and concerns around accessing paediatric unscheduled healthcare during COVID-19: a cross-sectional survey. IJERPH 17:9264. https://doi.org/10.3390/ijerph17249264

27. Roland D, Harwood R, Bishop N et al (2020) Children's emergency presentations during the COVID-19 pandemic. Lancet Child Adolesc Health 4:e32-e33. https://doi.org/10.1016/S23524642(20)30206-6

28. Bram JT, Johnson MA, Magee LC et al (2020) Where have all the fractures gone? The epidemiology of pediatric fractures during the COVID-19 pandemic. J Pediatr Orthop 40:373-379. https://doi. org/10.1097/BPO.0000000000001600

29. Baxter I, Hancock G, Clark M et al (2020) Paediatric orthopaedics in lockdown: a study on the effect of the SARS-Cov-2 pandemic on acute paediatric orthopaedics and trauma. Bone Joint Open 1:424 430. https://doi.org/10.1302/2633-1462.17.BJO-2020-0086.R1

30. Mann JA, Patel N, Bragg J et al (2020) Did children 'stay safe'? Evaluation of burns presentations to a children's emergency department during the period of COVID-19 school closures. Arch Dis Child. https://doi.org/10.1136/archdischild-2020-320015

Publisher's note Springer Nature remains neutral with regard to jurisdictional claims in published maps and institutional affiliations. 